\title{
ESTIMATION AND EVALUATION OF CHLOROPHYLL CONTENT AND CHLOROPHYLL STABILITY INDEX OF SOME ANTIALLERGENIC MEDICINAL PLANTS OF PARNER TAHSIL
}

\author{
Gitanjali Kakade and Sajan Khapke* \\ New Arts, Commerce and Science College, Parner -414302 (M. S.) \\ *Corresponding Author: sajankhapke@gmail.com
}

\begin{abstract}
Medicinal plants have been used from the Vedic era. For thousands of years, they have been used to treat and prevent many types of diseases along with epidemics. The study was aimed to understand chlorophyll content and chlorophyll stability index of some antiallergenic medicinal plants. This study is helpful to know the photosynthetic growth potential of the medicinal plants and to know the ability of plants to withstand in the adverse environmental conditions. Chlorophyll is most prominent and important pigment in plants. Chlorophyll shows structural similarities to human blood and hence it has many health benefits. The chlorophyll content was estimated by spectrophotometric method by using acetone as a solvent. The total chlorophyll content is higher in Acacia concinna $(0.685 \mathrm{mg} / \mathrm{gfw})$ and lower in Aloe barbadensis $(0.066 \mathrm{mg} / \mathrm{gfw})$. Bixa orellana shows higher chlorophyll stability index (CSI) i.e. 0.317 and lower in Lawsonia inermis i.e. 0.043.
\end{abstract}

Key words: - Chlorophyll, Chlorophyll Stability Index, Antiallergenic Medicinal Plants, Parner Tahsil

\section{INTRODUCTION:}

From ancient period plant parts are used in traditional medicine to cure various diseases. Some medicinal plants are specifically used to treat allergic disorders. Allergy is a prominent problem worldwide. Allergy is caused by allergens like dust mites, pollens etc. Some common medicinal plants show antiallergenic activities, they are Aloe barbadensis (Mill.) (Gwarpatha), Azadirachta indica (Linn.) (Neem), Acacia concinna (Shikakai), Adhatoda vasica (Nees.) (Adulsa), Aegle marmelos (Corr.) (Bel), Bauhinia racemosa (Lam.) (Aapata), Bixa orellana (Linn.) (Shendari), Butea monosperma (Lam.) (Palas), Cydonia oblonga (Mill.) (Dogri) and Lawsonia inermis (Linn.) (Mehandi). All plants are easily available in our area. Almost all parts of the plants i.e. stem, bark, branches, leaves, fruits, seeds etc. are medicinally important. The stem bark extract of Neem shows anti-inflammatory activity
(Tidjani et al, 1989). Medicinal plants are effective against various diseases because of their pharmacological efficacy which depends on their elemental concentrations. Phytochemical like primary and secondary metabolites are formed in various combinations of major, minor and trace elements which play curative and preventive role in most of the dangerous diseases. (Pawar and Kamble, 2016). The lower concentration of chlorophyll content of leaf can directly control the photosynthetic ability (Curran et al, 1990, Filella et al 1995). Chlorophyll stability index is an ability of the plants to withstand the adverse conditions and hence it most important parameter of the plants. Under adverse environmental conditions like water scarcity, salt stress, aging etc, the chlorophylls is degraded fast, which affects photosynthesis process. The degree of degradation of 
chlorophyll varies from plant to plant. In certain plants chlorophylls are more stable under adverse conditions. Such plant species shows high chlorophyll stability index (Pawar and Kamble, 2015). Under the circumstances it is essential to observe chlorophyll stability index of medicinally important plants. The chlorophyll has a key role in photosynthesis process. From the recent research it is clear that chlorophyll has many medicinal properties like anti-mutagenic, antiartherogenic, antioxidant, anti-carcinogenic, anti-diabetic, antibacterial, anti-fungal, antiviral, anti-inflammatory, anti-allergic activities.

\section{MATERIAL AND METHODS:}

\section{Plant material:}

Healthy fresh green leaves of Aloe barbadensis, Azadirachta indica, Acacia concinna, Adhatoda vasica, Aegle marmelos, Bauhinia racemosa, Bixa orellana, Butea monosperma, Cydonia oblonga and Lawsonia inermis have been used as plant materials for experimentation.

Extraction and Estimation of Chlorophyll: Chlorophyll were extracted and estimated by Arnon's (1949) method. The green leaves from medicinal plants were cut into small pieces and $0.1 \mathrm{~g}$ of sample was homogenized in chilled $80 \%$ acetone in mortar and pestle. The acetone extract was filtered through Whatman No. 1 filter paper. The final volume of the extract was made to $20 \mathrm{ml}$ with $80 \%$ acetone. The absorbance of acetone extract was read at 645 and $663 \mathrm{~nm}$ using UV-visible spectrophotometer 117 (Systronics) using 80 per cent acetone as a reference.

\section{Chlorophyll Stability Index (CSI)}

Chlorophyll Stability Index was estimated by using the method of Murthy and Majumdar (1962) and calculated by following formula, CSI $=$ Total Chlorophyll content of heated plant material Total Chlorophyll content of fresh plant material

\section{RESULTS AND DISCUSSION:}

The amount of chl.a, chl.b, total chlorophyll content and chlorophyll stability index (CSI) as per calculations are presented in Table No 1 . It was found that Acacia concinna have the highest amount of total chlorophyll content i.e. $0.685 \mathrm{mg} / \mathrm{gfw}$ followed by Bixa orellana $(0.568$ $\mathrm{mg} / \mathrm{gfw})$, Adhatoda vasica $(0.433 \mathrm{mg} / \mathrm{gfw})$, Cydonia oblonga (0.355mg/gfw), Butea monosperma (0.295mg/gfw), Azadirachta indica $(0.282 \mathrm{mg} / \mathrm{gfw}), \quad$ Aegle marmelos (0.251mg/gfw), Bauhinia racemosa (0.250mg/gfw), Lawsonia inermis (0.116mg/gfw) and Aloe barbadensis (0.066mg/gfw) (Table No 1). Pawar and Kamble, 2015 evaluated chlorophyll content and chlorophyll stability index of some antiallergenic medicinal plants.

Chlorophyll is one of the primary compounds having capacity to harvest sunlight for photosynthesis. Chlorophyll content in plants indicates the growth potential and photosynthetic capability of the plants (Jain and Gadre, 1998). Primary metabolites are the precursor of secondary metabolites. Secondary metabolites like flavonoids, alkaloids, lipids, polyphenols etc play important role in the formulation of drug. Chlorophyll stability index (CSI) of plant $B$. orellana, A. concinna, C. oblonga, B. racemosa, A. marmelos, B. monosperma, A. vasica, A. indica, $A$. barbadensis and $L$. inermis are $0.317,0.266,0.242,0.235,0.230,0.212$, $0.136,0.120,0.052$ and 0.043 respectively. $B$. orellana shows highest chlorophyll stability index (0.317) and $L$. inermis have lowest chlorophyll stability index (0.043).

\section{CONCLUSION:}

In the present study all the ten anti-allergenic medicinal plants of Parner tahsil under study showed that they have higher photosynthetic capability and growth potential due to higher 
concentration in chlorophyll content. All plants have ability to withstand the adverse environmental conditions because they show high chlorophyll stability index (CSI). Among these ten plants $A$. concinna have high total chlorophyll content and Bixa orellana have high chlorophyll stability index than remaining nine plants.

\section{ACKNOWLEDGEMENT:}

The authors are thankful to Prin. Dr. R. K. Aher and Dr. R. N. Deshmukh, Head, Dept. of Botany, New Arts, Commerce and Science College, Parner for continuous encouragement and facilities provided during present investigation.

\section{REFERENCES:}

Arnon D.I. (1949): Copper enzymes in isolated chloroplasts polyphenol oxidase in Beta vulgaris. Plant Physiol. 24:1-15.

Curran P.J., Dungan J.L. and Gholz H.L. (1990). Exploring the relationship between reflectance red edge and chlorophyll content in slash pine. Tree Physiology 7: 33-48.

Filella I., Serrano L., Serra J. and Peñuelas J. (1995). Evaluating wheat nitrogen status with canopy reflectance indices and discriminant analysis. Crop Science 35: 1400-1405.

Jain M. and R. Gadre, (1998). Inhibition of chlorophyll synthesis and enzymes of nitrogen assimilation by selenite in excised maize leaf segments during greening. Water Air Soil, Pollut. 104: 161-166.

Murthy K.S. and Majumdar S.K. (1962): Modification of the technique for determination of chlorophyll stability index in relation to studies of drought resistance in rice. Current Science.31:470- 471.

Pawar S.G. and Kamble V.M. (2015). Evaluation of chlorophyll content and chlorophyll stability index of some antiallergenic medicinal plants. Asian Jr. of Multidisci. Studies. 3(1):17-19

Pawar S.G. and Kamble V.M. (2016). Elemental analysis of anti-allergenic indigenous plants and their possible correlation with therapeutic activity. Internat. Jr. of Pharmaceutical and Clinical Res. 8(9): 1290-1295 8. Tidjani M.A., Dupont C. and Wepierre J. (1989). J.Planta Med, Phytother. 23:259-266.

Table No 1: Chl.a, Chl.b, Total Chlorophyll Content and Chlorophyll Stability Index (CSI).

\begin{tabular}{|c|l|c|c|c|c|}
\hline \multirow{2}{*}{$\begin{array}{c}\text { Sr. } \\
\text { No. }\end{array}$} & \multirow{2}{*}{ Name of Plant } & Chl.a & Chl.b & Total Chl. & \multirow{2}{*}{ CSI } \\
\cline { 2 - 5 } & Aloe barbadensis & 0.035 & 0.031 & 0.066 & 0.052 \\
\hline 2 & Azadirachta indica & 0.143 & 0.138 & 0.282 & 0.120 \\
\hline 3 & Acacia concinna & 0.320 & 0.365 & 0.685 & 0.266 \\
\hline 4 & Adhatoda vasica & 0.246 & 0.187 & 0.433 & 0.136 \\
\hline 5 & Aegle marmelos & 0.128 & 0.122 & 0.251 & 0.230 \\
\hline 6 & Bauhinia racemosa & 0.118 & 0.131 & 0.250 & 0.235 \\
\hline 7 & Bixa orellana & 0.338 & 0.230 & 0.568 & 0.317 \\
\hline 8 & Butea monosperma & 0.181 & 0.113 & 0.295 & 0.212 \\
\hline 9 & Cydonia oblonga & 0.199 & 0.156 & 0.355 & 0.242 \\
\hline 10 & Lawsonia inermis & 0.052 & 0.063 & 0.116 & 0.043 \\
\hline
\end{tabular}

